\title{
ALGUNAS REFLEXIONES Y PROPUESTAS SOBRE EL TRABAJO EN LEXICOGRAFÍA GENERAL DEL GRIEGO ANTIGUO*
}

\author{
EUGENIO R. LUJÁN \\ Universidad Complutense de Madrid
}

El artículo propone la adaptación al trabajo en Lexicografía griega general del griego antiguo de algunos de los métodos y estrategias utilizados para la confección de diccionarios de lenguas modernas. También se estudia el impacto en el trabajo lexicográfico de los avances en otras áreas de la Filología Griega, especialmente la edición de textos y la crítica textual.

Palabras-clave: Lexicografía; diccionarios; griego antiguo; crítica textual.
This paper shows how some methods and strategies used for the making of dictionaries of modern languages can be applied to the lexicographical practice of ancient Greek. It is also anaysed what impact recent developments in other areas of Greek philology - especially text edition and textual criticism - have on lexicographical work.

Keywords: Lexicography; dictionaries; ancient Greek; textual criticism.

\section{Introducción}

El objetivo de este trabajo es presentar algunas ideas y propuestas sobre la práctica de la lexicografía griega y analizar las posibilidades de incorporación al trabajo específico en lexicografía del griego antiguo de algunos planteamientos recientes en la lexicografia de otras lenguas, especialmente de las lenguas modernas, así como en otras disciplinas de la Filología Griega.

* Las ideas que aparecen en este artículo deben atribuirse únicamente a su autor y no necesariamente son compartidas por otros miembros del equipo de lexicógrafos que, bajo la dirección del Prof. F. R. Adrados, elaboran el Diccionario Griego-Español (DGE) en el Instituto de Filología del C.S.I.C. Para los principios en que se basa este diccionario véase la introducción del volumen I, Madrid 1980, así como el libro Introducción a la lexicografía griega, Madrid 1977, y, entre otros trabajos, el artículo de F. R. Adrados - J. Rodríguez Somolinos, «Diccionario Griego-Español, vol. V», Museum Criticum 30-31, 1995-96, pp. 301-317. Más bibliografía acerca del $D G E$ puede encontrarse en su "página web": www.filol.csic.es/dge/bib/bib.htm.

EMERITA. Revista de Lingüística y Filología Clásica (EM) - LXX 2, 2002

pp. $257-282$ 
Para comenzar, conviene precisar los límites del trabajo posible en lexicografía del griego antiguo y para ello resulta necesario detenerse un momento a plantearse qué tipos de diccionario son factibles en el caso del griego antiguo ${ }^{1}$. Para una lengua moderna viva, es decir, para lo que se suele denominar una lengua "de informantes" por oposición a una lengua "de corpus", podemos establecer una distinción entre diccionarios generales y diccionarios segmentales ${ }^{2}$. Los diccionarios generales se ocupan del léxico de una lengua en su conjunto, aunque pueden tener diferente cobertura y extensión en función de que intenten ocuparse únicamente del vocabulario central ("core vocabulary") de esa lengua o bien incorporar más términos de las zonas periféricas. Por definición en una lengua viva resulta imposible compilar un diccionario total, pues la creación léxica es un proceso vivo que da lugar continuamente a nuevas palabras.

La segunda clase de diccionarios la integran los diccionarios especiales, cuyo ejemplo más característico lo constituyen los diccionarios técnicos, que normalmente pretenden abordar de forma exhaustiva parcelas muy concretas del léxico de una lengua $\mathrm{y}$, además, normalmente dejando fuera precisamente el vocabulario central conocido y compartido por todos los hablantes de esa lengua. Aquí se incluyen también los diccionarios de los diferentes registros, los diccionarios de jergas, etc.

¿Cuál es, en función de esta clasificación, la situación del griego antiguo? No hay ningún problema con los diccionarios de este segundo tipo. Obras como las clásicas de Thompson sobre los nombres de pájaros y peces ${ }^{3}$, o las de Mügler sobre la terminología geométrica y óptica ${ }^{4}$, entre otras muchas son bien conocidas. Entre los proyectos importantes actualmente en curso clasificables dentro de este tipo se encuentra, por ejemplo, el Lexicon Vasorum Graecorum dirigido por P. Radici Colace ${ }^{5}$.

Sin embargo, en el ámbito de la Filología Clásica es muy frecuente un tipo de diccionario que no encaja en ninguno de esos dos tipos, el

1 Para otras clasificaciones de los diferentes tipos de diccionarios pueden verse, entre otros: G. Haensch — L. Wolf - S. Ettinger — R. Werner, La lexicografia, Madrid, 1982, pp. 95-187.

2 Véase K. Opitz, «On dictionaries for special registers», en: R. R. K. Hartmann (ed.), Lexicography: Principles and Practice, Londres, 1983, pp. 53-64.

3 D'A. Thompson, A Glossary of Greek Birds, Londres, 1936; A Glossary of Greek Fishes, Londres, 1947.

4 Ch. Mügler, Dictionnaire historique de la terminologie géometrique des Grecs, París, 1958; Dictionnaire historique de la terminologie optique des Grecs, París, 1964.

5 P. Radici Colace, (dir.), Lexicon Vasorum Graecorum, vols.1-2 ( $\alpha-\beta)$, Pisa, 1992-1997. 
Diccionario de Autor, de Género Literario o de un conjunto de obras. Se trata de un tipo de diccionario especial en tanto que limita el objeto de su estudio pero, por regla general, incluye también ese vocabulario central de la lengua en la medida en que lo haya utilizado el autor en cuestión. La mayor o menor extensión hacia la periferia del vocabulario de una lengua que se dé en estos diccionarios dependerá del propio autor y del tipo de obras cuyo léxico se recoge, pues Arquímedes y Euclides, por ejemplo, por el propio contenido de sus obras, utilizarán un léxico más técnico $\mathrm{y}$, por tanto, más alejado hacia la periferia, que, por ejemplo, los novelistas griegos.

En cuanto a los diccionarios generales, el planteamiento que se suele hacer en las lenguas modernas no es frecuente en el caso de la lexicografía griega contemporánea. Los diccionarios de cobertura limitada no suelen seleccionar el léxico del que se ocupan en función de criterios como la frecuencia de aparición, sino por el criterio de los autores griegos "más importantes", es decir, aquellos habitualmente leídos y comentados en las clases de griego. Por referirme a un ejemplo español bien conocido, el diccionario de J. M. Pabón ${ }^{6}$, el utilizado habitualmente en España en los últimos años para el aprendizaje del griego en sus niveles elementales, selecciona el léxico de los poemas homéricos, Heródoto, Tucídides, las obras mayores de Jenofonte, algunos diálogos de Platón, Sófocles, Anacreonte, Esopo, tres discursos de Demóstenes, algunas obras de Luciano y la totalidad del Nuevo Testamento. Y esta es la práctica habitual, de modo que estos diccionarios se convierten en una variante del tipo que acabamos de describir en tanto que vienen a ser la suma de varios diccionarios de autor.

En el caso del griego antiguo, frente a lo que afirmábamos para los diccionarios generales de las lenguas modernas, sí que resultaría concebible, en principio, la realización de un diccionario total, dado que nos encontramos ante una lengua de corpus, por inmenso que pueda ser un corpus como el del griego aun ateniéndonos a unos límites como los que maneja el Diccionario Griego-Español (DGE), que aspira a cubrir todo el léxico griego desde época micénica hasta el siglo VI d.C. Sin embargo, este hecho no debe producir la ilusión de que se puede compilar ese supuesto diccionario total, pues el propio carácter de lengua de corpus y, por tanto, de testimonio limitado supone que haya parcelas del léxico griego que no se nos han conservado o que sólo lo han hecho de forma muy limitada. Esto es lo que

6 J. M. Pabón, Diccionario Manual Griego-Español, Barcelona, 1981 (14. ${ }^{\text {a ed.). }}$ 
ocurre, por ejemplo, con el léxico coloquial, el léxico dialectal de la mayor parte de los dialectos griegos o léxicos técnicos como el de la agricultura, el náutico o el del trabajo del metal. Un diccionario que pretenda abarcar la totalidad del léxico griego conservado presentará, por tanto, lagunas debidas a la propia documentación que nos resulta posible manejar.

\section{Fase de recopilación de materiales}

Para comprender adecuadamente la investigación en lexicografía griega hay que plantearse también cuáles son las relaciones entre los tres tipos de diccionario a los que he aludido más arriba, lo que, además, nos hace adentrarnos ya en la primera de las tres fases en que los estudios sobre lexicografía suelen dividir el proceso de elaboración de un diccionario: la recopilación de materiales, a la que deben seguir después las de organización de esos materiales y su presentación al usuario del diccionario ${ }^{7}$.

Para la recopilación de materiales el lexicógrafo cuenta con dos tipos de fuentes primordiales: las fuentes directas y las fuentes indirectas. Las fuentes indirectas son los trabajos lexicográficos anteriores, pues en lenguas como el griego contamos con una larga tradición lexicográfica que se remonta a la Antigüedad misma. De esta manera, un diccionario como el $D G E$ se inserta dentro de esa tradición y tiene como su antecesor inmediato el que a la espera de su propia finalización sigue siendo hoy por hoy el diccionario más completo de griego antiguo, el de Lidell, Scott y Jones ${ }^{8}$. En la lexicografía de las lenguas modernas donde, salvo brillantes excepciones como el reciente Diccionario del español actual de Manuel Seco, Olimpia Andrés y Gabino Ramos ${ }^{9}$, es tradicional la utilización de diccionarios anteriores, que a veces se ve completada por un trabajo de revisión directa de algunos textos, pero, en cualquier caso, lo primordial es la recopilación a partir de las fuentes indirectas. En el caso de la lexicografía griega, precisamente uno de los rasgos que distinguen a la lexicografía científica moderna es que ésta hace uso de las fuentes indirectas como punto de partida de la investigación, pero los significados y referencias se comprueban en las fuentes directas, que en esta caso, por la propia naturaleza del objeto de la investigación son

7 Sobre las fases de elaboración de un diccionario véase también Haensch et alii, ob. cit. en n. 2, pp. 427-430.

8 Sobre la historia de los diccionarios de griego véase J. López Facal, «Historia de la lexicografía griega moderna» en: Introducción a la lexicografia griega, Madrid, 1977, pp. 107-142.

9 M. Seco - O. Andrés - G. Ramos, Diccionario del español actual, 2 vols., Madrid, 1999. 
siempre fuentes escritas, los textos.

De todas formas, antes de abordar en qué consiste el "trabajo de campo" en lexicografía griega conviene detenerse a considerar cuáles pueden ser los criterios de utilización en un diccionario general del griego antiguo de las fuentes indirectas antiguas, es decir, de la propia tradición lexicográfica antigua del griego ${ }^{10}$. La tradición lexicográfica antigua del griego es enorme y de una gran complejidad y se plasma fundamentalmente en dos tipos de realizaciones: los léxicos o glosarios, por un lado, y los escolios, por otro. No abordaré aquí la cuestión de la historia y las relaciones entre los diferentes léxicos antiguos conservados, de enorme complejidad y que desbordaría con muchos los objetivos de este trabajo ${ }^{11}$, sino que ahora me interesa señalar en qué medida se pueden y se deben utilizar estas fuentes antiguas indirectas en la elaboración de un diccionario general del griego antiguo. Aquí podemos distinguir diferentes casos, que merecen, lógicamente, tratamientos diferentes:

a) La palabra sólo se encuentra atestiguada en léxicos antiguos.

b) El sentido sólo se encuentra atestiguado en los léxicos antiguos.

c) La aparición en un léxico es anterior a otra documentación.

d) La aparición en un léxico es posterior a otra documentación.

Va de suyo que un diccionario general del griego antiguo debe recoger todas las palabras que únicamente se encuentran atestiguadas en los léxicos antiguos, ya que debemos suponer que formaban parte del caudal léxico de la lengua, solo que por azares en la transmisión textual del griego únicamente se nos han conservado en esas obras ${ }^{12}$. Los ejemplos pueden multiplicarse, pues Hesiquio o Pólux, por citar dos de los principales lexicógrafos antiguos, nos han transmitido abundantes palabras que sólo conocemos gracias a ellos, en algún caso con el testimonio adicional de otra obra lexicográfica, como el Etymologicum Magnum. Baste señalar, en el comienzo de la

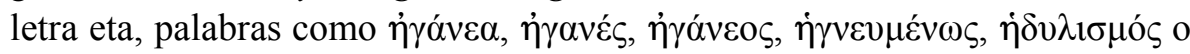

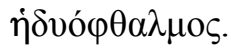

10 Sobre la utilización de las fuentes indirectas en lexicográfica histórica véanse las reflexiones a propósito del inglés de N. E. Osselton, Chosen Words (Past and Present Problems for Dictionary Makers), Exeter, 1997 [reimpr. corregida], pp. 137-147.

11 Remito para ello al artículo de C. Serrano, «Historia de la lexicografía griega antigua y medieval», en: Introducción a la lexicografía griega, Madrid, 1977, pp. 61-106.

12 Naturalmente esta afirmación no se refiere a las palabras que claramente deben su existencia a un error en la tradición manuscrita. 
El segundo caso resulta ya más problemático, puesto que hay que plantearse la pregunta de si el sentido que transmiten los lexicógrafos existió realmente o simplemente se debe a una mala interpretación del significado de la palabra en los textos literarios. Esto resulta especialmente frecuente en el caso de palabras homéricas para las que los lexicógrafos antiguos ofrecen interpretaciones que no se corresponden con las admitidas hoy en día. En casos como éste el lexicógrafo debería hacerse eco de la interpretación antigua, pero dejando claro que no se trata de otro sentido de la misma palabra sino simplemente de una interpretación diferente. Así, por ejemplo, muchos de los gramáticos antiguos (Hdn.Gr.2.236, Orio s.u. है $\theta \varepsilon ı \rho \alpha$,

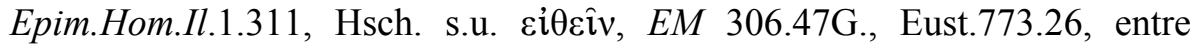
otros) interpretan las formas de $\ddot{\varepsilon} \theta \omega$ como un presente de $\varepsilon \grave{\imath} \omega \theta \alpha$ 'estar acostumbrado', 'soler', mientras que modernamente se suele preferir una interpretación alternativa, que también cuenta con apoyos en la tradición antigua (cf. $\left.\ddot{\varepsilon} \theta \varepsilon \imath^{\cdot} \varphi \theta \varepsilon i ́ \rho \varepsilon 1, \dot{\varepsilon} \rho \varepsilon \theta i \zeta \varepsilon \imath\right)$ y que supone entenderlo como derivado de una raíz *wedh y con el sentido de 'devastar, destruir'. Aunque se prefiera esta segunda interpretación un diccionario general del griego antiguo no debería dejar de recoger también la primera.

Otro caso similar, pero a la vez diferente, se da cuando no parece que el sentido que atribuyen los lexicógrafos a una palabra se pueda derivar de su utilización en los textos, lo que, naturalmente, hace que también resulte necesaria la inclusión de ese otro sentido. Así sucede, por ejemplo, con una palabra como غ̇̀ $\dot{\varphi} \varphi \alpha \varsigma$, cuyos significados 'marfil' y 'elefante' están abundantemente atestiguados en la literatura griega y que puede referirse también a un tipo de piedra, probablemente el marfil fósil (Thphr., Lap. 37), y a una clase de copa o cuerno para beber (Damox. 1.1, Epin. 2.4). Pues bien, a estos sentidos hay que añadir el de 'lana blanca' que únicamente conocemos por una glosa de Hesiquio, donde, s.u. Ė $\lambda \dot{\varepsilon} \varphi \alpha v \tau \alpha$, se nos da la interpretación $\lambda \varepsilon v \kappa \alpha \grave{~ \varepsilon ̌ p l \alpha, ~ q u e ~ r e s u l t a ~ n e c e s a r i o ~ r e c o g e r . ~}$

El tercer supuesto, que la documentación en los lexicógrafos sea anterior a la documentación en otro tipo de textos, tampoco ofrece ninguna dificultad: necesariamente habrá de recogerse ese testimonio dentro del artículo o del apartado del artículo que corresponda, y generalmente en cabeza del mismo, de modo que el usuario del diccionario pueda acceder a la información de que ésa es la aparición más antigua documentada de la palabra griega en ese sentido. Este supuesto no es en la práctica demasiado frecuente, aunque sí se puede ofrecer algún ejemplo como $\gamma \lambda v \kappa u ́ \varphi \omega v o \varsigma$ 'de voz dulce, suave', 
atestiguado ya en Pólux (Poll. 2.113) pero que en textos literarios no se encuentra hasta Atanasio de Alejandría (Ath.Al. M. 27.208D).

El cuarto supuesto, en cambio, es el que queda más abierto a una cierta discrecionalidad en el tratamiento de las citas procedentes de lexicógrafos. En general, el criterio que habrá de seguirse es de la frecuencia de aparición de la palabra. Así, en palabras de alta frecuencia en los textos griegos conservados resulta claramente innecesaria la inclusión de las referencias a los lexicógrafos antiguos. Nada aporta a un diccionario general de griego antiguo, por ejemplo, incluir las citas de Hesiquio referidas a palabras como

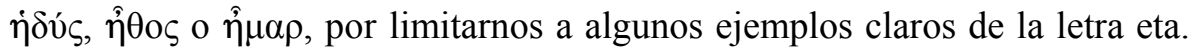
En cambio, sí que puede resultar interesante añadir al final de palabras de baja frecuencia la referencia a los lexicógrafos, que, en el caso de hápax de los trágicos o los cómicos, por ejemplo, sirve en cierta medida para corroborar la propia existencia de la palabra aunque la interpretación que ofrece el lexicógrafo antiguo realmente no añada nada desde el punto de vista de la interpretación y de la traducción de la palabra en cuestión. Esto sucede, por

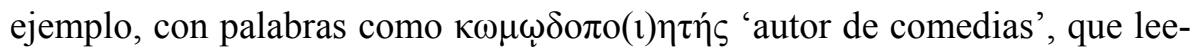
mos en Ar., Pax 734 y en Poll. 4.111, además de en los escolios al pasaje. O

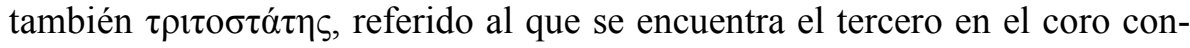
tando a partir del corifeo, palabra que aparece en la Metafísica de Aristóteles (Arist.Metaph.1018 28) y que sólo vuelve a estar atestiguada en toda la literatura griega en Pólux (Poll.4.106) aparte de en los propios comentaristas de Aristóteles.

Paso ahora a ocuparme de lo que con toda propiedad podemos llamar el "trabajo de campo" en lexicografía griega, es decir, el estudio directo de los textos. En la lexicografía de las lenguas modernas se ha hablado de "trabajo de campo" para referirse a la recopilación de materiales léxicos a partir del estudio directo de la utilización que los hablantes de una lengua hacen de ella ${ }^{13}$. En lexicografía griega, naturalmente, el "trabajo de campo" lo constituye el análisis de los textos de todo tipo que han llegado hasta nosotros. Para este trabajo de campo constituyen una guía las fuentes indirectas, es decir, las obras lexicográficas anteriores (ya sean diccionarios, índices o concordancias) y los estudios particulares de léxico. Resulta fundamental, por tanto, para la elaboración de un diccionario general de

13 Sobre el trabajo de campo en lexicografía véase H. Béjoint, «On field-work in lexicography», en: R. R. K. Hartmann (ed.), Lexicography: Principles and Practice, Londres, 1983, pp. 67-76. 
griego el manejo de todos esos instrumentos que se ocupan de forma especial de parcelas del léxico de una lengua ${ }^{14}$.

A estos instrumentos que podríamos denominar "tradicionales" hay que añadir una herramienta de gran potencia tanto por la amplitud de autores que abarca como por el soporte en que aparece. Se trata, naturalmente, del índice del Thesaurus Linguae Graecae de Irvine, el TLG. La aplicación de la informática al trabajo lexicográfico es ya una realidad y de su utilización específica en el campo de la Filología Griega son una buena muestra los últimos volúmenes del $D G E^{15}$. Esta fructífera aplicación de las herramientas informáticas a la investigación en lexicografía puede desarrollarse todavía más, ya no únicamente para poder aumentar la documentación de palabras de baja frecuencia y para la localización de hápax que hasta ahora no habían sido recogidos en los diccionarios de griego, sino para sistematizar e introducir criterios en la selección de materiales en palabras de gran frecuencia. Me limitaré a ofrecer un ejemplo: las posibilidades de utilización del TLG en la selección de locuciones y clichés, para lo que pueden servirnos de referencia los métodos de trabajo que se están poniendo en práctica en las lenguas modernas.

14 Para la relación de las obras más importantes en este terreno remito al trabajo de actualización de J. Rodríguez Somolinos, «La lexicografía griega en los últimos años», Estudios Clásicos 100, 1991, pp. 83-118, así como al apartado dedicado a la "lexicografía especial" en el libro de D. Lara, Iniciación a la lexicografia griega, Madrid, 1997, pp. 18-35. Para los léxicos de autores y obras tenemos ahora el libro de P. Boned - J. Rodríguez Somolinos et alii, Repertorio bibliográfico de la lexicografía griega, Madrid, 2000, con sus actualizaciones en la página web del $D G E$ (http://www.filol.csic.es/dge/blg/blgsint.htm).

15 Sobre la utilización de los recursos informáticos en el $D G E$ pueden verse: J. López Facal, «Ordenadores y lexicografía griega. El Banco de Datos», en: Introducción a la lexicografía griega, Madrid, 1977, pp. 209-215; J. López Facal, «The use of computers in the Greek-Spanish Dictionary», en: The Possibilities and Limits of the Computers in Producing and Publishing Dictionaries. Proceedings of the European Science Foundation Workshop, Pisa, 1981 (=Linguistica Computazionale 3), 1983, pp. 97-105; F. R. Adrados, «The use of computers in the Diccionario Griego-Español», en: Standardization in Computerized Lexicography, Saarbrücken, 1986, pp. 161-170; J. Rodríguez Somolinos - I. Álvarez, «Informática y lexicografía: la experiencia del Diccionario Griego-Español», Emerita 59, 1991, pp. 81-99; F. R. Adrados - J. Rodríguez Somolinos, «The TLG data bank, the DGE and Greek Lexicography», Emerita 62, 1994, pp. 241-251. Planteamientos generales y aplicaciones a otras lenguas pueden encontrarse entre otros, en: E. F. Knowles, «The computer in Lexicography», en: F. J. Hausmann - O. Reichmann - H. E. Wiegand - L. Zgusta (eds.), Wörterbücher. Dictionaries. Dictionnaires. Ein internazionales Handbuch zur Lexicographie, 3 vols., Berlín y Nueva York, 1989-1991, pp. 1643-1672; G. Gorcy, «L'informatisation d'un dictionnaire: l'exemple du Trésor de la langue française», ibid., pp. 1672-1678. 
En un interesante trabajo sobre el procesamiento informático de los corpora textuales para la investigación en lexicografía Martin, Al y van Sterkenburg ${ }^{16}$ se han ocupado, entre otras cuestiones, de este problema y las ideas que allí ofrecen son, en mi opinión, muy aplicables a la investigación del griego antiguo. En el estudio de las lenguas modernas cada vez es más frecuente trabajar sobre corpora textuales, lo que, para el tema que nos ocupa, implica no dejar la selección de locuciones y clichés al criterio del redactor o de la persona encargada de preparar los materiales para la redacción, con base únicamente en su propia competencia lingüística, o a la autoridad de la tradición lexicográfica. Los criterios que se manejan para determinar la existencia de una frase hecha, locución o cliché están basados en la frecuencia de aparición, que ha de ser significativamente superior a la frecuencia esperable. En lexicografía, no sólo del griego, sino en general, los autores citados señalaban que hasta ese momento ése había sido un método de investigación no demasiado explotado, debido, principalmente, a la ausencia de buenos corpora y a las dificultades para procesar volúmenes de información como los que requieren estas investigaciones. Sin embargo, hoy en día los corpora están disponibles para las principales lenguas y las mejoras en la velocidad de los procesadores informáticos hacen que resulte un tipo de investigación completamente viable. Kornelius ${ }^{17}$ ha planteado para el caso del alemán incluso la metodología para la realización de un diccionario electrónico de giros y frases hechas. Sin llegar a esos extremos, para el trabajo en un diccionario general del griego, la existencia del TLG permite plantearse investigaciones en esta línea, que permitirían una aproximación mucho más sistemática al tratamiento de las unidades superiores a la palabra dentro de los lemas de alta frecuencia. A efectos prácticos, habría que dar los siguientes pasos para poder desarrollar estas investigaciones de una manera eficaz:

Estudiar cuál es la distancia máxima, medida en número de palabras, a la que normalmente aparecen las palabras que pueden formar un cliché con la palabra base o de referencia. Por ejemplo, normalmente un genitivo aparecerá dentro de un radio de cinco palabras respecto del nombre al que determina. Una distancia

16 W. J. R. Martin - B. F. P. Al - P. J. G. Van Sterkenburg, «On the processing of a text corpus», en: R. R. K. Hartmann, (ed.), Lexicography: Principles and Practice, Londres, 1983, pp. 77-87.

17 J. Kornelius, «Vom Printwörterbuch zum elektronischen Kollokationswörterbuch. Theoretische, methodische und praktische Überlegungen zur Erstellung eines Kollokationswörterbuchs», Lexicographica 11, 1995, pp. 153-171. 
quizá ligeramente mayor habría que considerar para un verbo con su complemento. Dependiendo del tipo de relación sintáctica que pueda existir entre las palabras habrá que tener en cuenta en ocasiones que la segunda palabra puede aparecer tanto por delante como por detrás de la palabra de referencia o bien, sólo delante o sólo detrás.

Una vez determinado ese radio, partiendo de las apariciones de la palabra base, las cuales pueden localizarse a través del índice del TLG, mediante la realización de la programación necesaria, se extraen a un fichero de forma automática las palabras incluidas en ese radio.

A partir de ese fichero y utilizando alguna de las herramientas informáticas ya disponibles para la elaboración de índices, hay que realizar un cómputo de la frecuencia de aparición de las palabras dentro de ese radio y ordenarlas por orden decreciente de frecuencia de aparición. Las situadas en los primeros niveles de frecuencia, excluyendo, en su caso, artículos, preposiciones o conjunciones, serán las que con más probabilidad constituyan clichés y locuciones ${ }^{18}$.

El lexicógrafo debe seleccionar las citas que, de acuerdo con los criterios habituales, considere más importante incluir para documentar la locución o cliché en cuestión, así como, ya en las fases de organización y presentación del artículo, decidir si debe o no aportar una traducción e incorporar las locuciones y clichés con las citas que considere adecuadas en el lugar apropiado del artículo.

Veamos con un ejemplo concreto cuál es la repercusión que esta metodología puede tener para el trabajo en lexicografía griega. En el LSJ

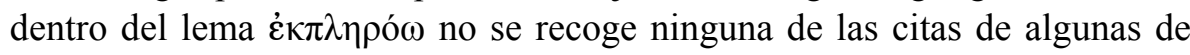
las expresiones más frecuentes en las que se utiliza este verbo. Naturalmente, dado el momento y los medios con que se contaba cuando se redactó ese diccionario no resultaba esperable que se pudiera hacer un tratamiento estadístico de las apariciones de esa palabra en toda la literatura griega, lo que, como acabamos de ver, actualmente sí es posible y resulta, por tanto, exigible en una obra lexicográfica que aspire a constituirse en referencia.

18 Como se ve, no planteo en ninguna de las fases la lematización de las formas que se encuentran en el radio de palabras en cuestión y esto por razones de índole teórica y práctica. Desde el punto de vista práctico hoy por hoy resulta imposible realizar una lematización automática y, además, salvo excepciones muy puntuales, una ordenación alfabética de las formas acompañada de la indicación de la frecuencia con la que aparecen dentro de ese radio bastará para que el lexicógrafo pudiera tener una visión de conjunto de la frecuencia de cada palabra (no ya de sus formas). Por otra parte, la mayoría de las veces la lematización de las formas no resulta necesaria, ya que si se trata de clichés o frases hechas el término que nos puede interesar estará siempre en el mismo caso (complemento directo de un verbo en acusativo, genitivo que acompaña a un nombre, etc.). 


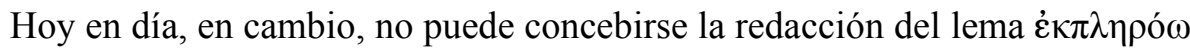
sin que en él se recojan, entre otras, las siguientes expresiones:

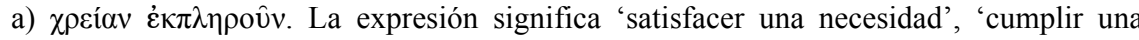
función' y puede aparecer tanto con el complemento directo en singular como en plural. Realizando una búsqueda que sólo ha tenido en cuenta las palabras en un radio de cinco palabras por delante y por detrás de las diferentes formas del verbo $\dot{\varepsilon} \kappa \pi \lambda \eta \rho o ́ \omega$ ha resultado que la expresión es utilizada más de veinte veces en los autores y obras que constituyen el corpus del DGE: Galeno, Oribasio, Arístides Quintiliano, Basilio de Cesarea, Clemente de Alejandría, Orígenes, Proclo, Simplicio, Pseudo-Macario, Juan Filopono y los escolios a los Trabajos y días de Hesíodo. Algunos ejemplos:

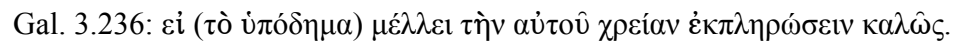

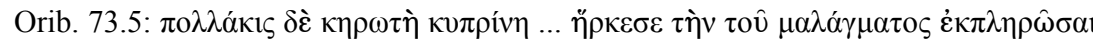

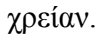

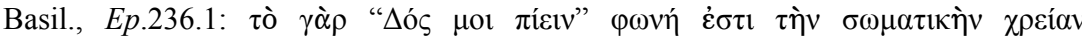
$\dot{\varepsilon} \kappa \pi \lambda \eta \rho о \hat{\sigma} \sigma \alpha$.

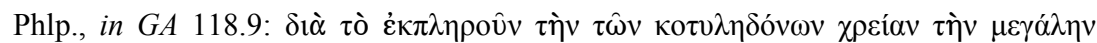
$\varphi \lambda \varepsilon \dot{\beta} \alpha$.

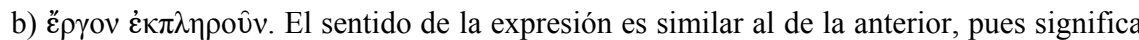
'llevar a cabo una acción', 'desempeñar una función'. En una búsqueda con las mismas condiciones que la anterior constatamos que la expresión se documenta más de quince veces en autores y obras citados en el DGE: Arriano, Alejandro de Afrodisias, PseudoMacario, Proclo, Pseudo-Justino Mártir, Teodoreto y los escolios a los Trabajos y días de Hesíodo. Algunos ejemplos:

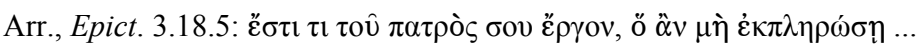

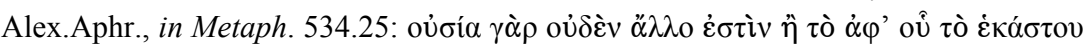

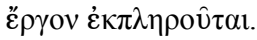

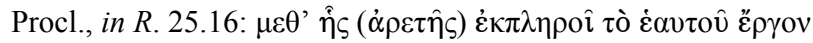

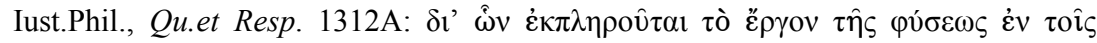

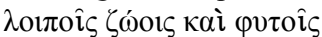

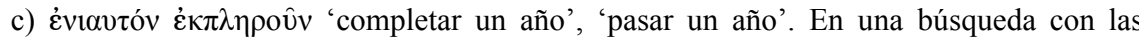
mismas condiciones que las anteriores se constata que la expresión se documenta al menos seis veces en los autores y obras citados por el $D G E$ : Filón de Alejandría, Dionisio de Halicarnaso, Eutropio, Peanio y los escolios a Píndaro. Veamos algunos ejemplos:

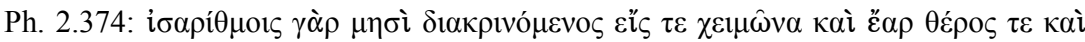

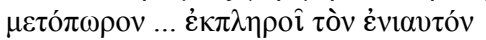

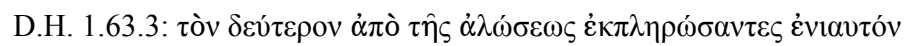

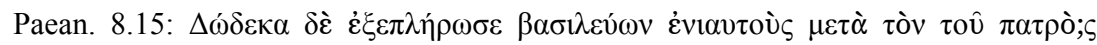

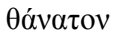

Veamos algún ejemplo más de la aplicación de esta metodología con otro verbo, $\dot{\varepsilon} \kappa \tau \varepsilon \lambda \dot{\varepsilon} \omega$. En este caso entre las expresiones que no podrían faltar en un diccionario general de griego antiguo se encuentran las siguientes, localizadas con los mismos criterios de búsqueda que para el verbo anterior: 


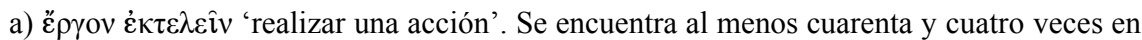
los autores y obras citados por el $D G E$, entre ellos Homero, Hesiodo, Sófocles, Teócrito, Galeno, Luciano, Dion Crisóstomo, Apiano, Eutecnio y Clemente de Alejandría. Algunos ejemplos:

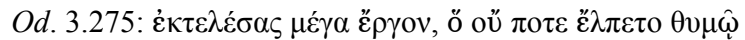

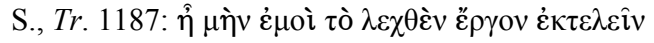

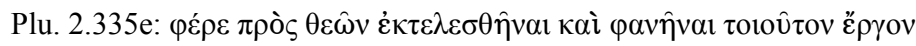

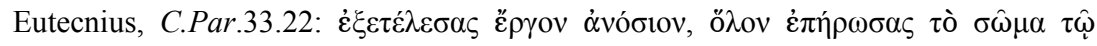
$\pi \alpha 1 \delta \grave{\imath} \tau \hat{\omega} v \dot{\alpha} v \alpha \gamma \kappa \alpha i ́ \omega v \dot{\alpha} \pi 0 \sigma \tau \varepsilon \rho \eta ́ \sigma \alpha \varsigma$

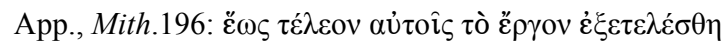

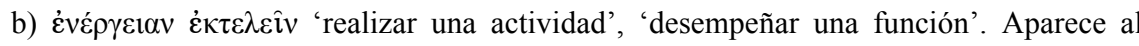
menos diez veces, en autores como Galeno, Pseudo-Justino Mártir, Basilio de Cesarea o Clemente de Alejandría. Algunos ejemplos:

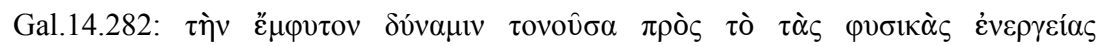
$\dot{\varepsilon} \kappa \tau \varepsilon \lambda \varepsilon \hat{\imath} \sigma \theta \alpha \mathrm{l} \kappa \alpha \lambda \hat{\omega} \varsigma$

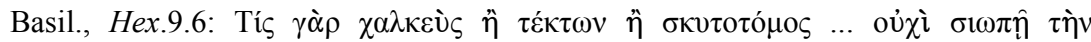

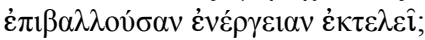

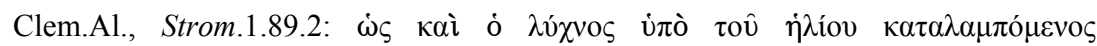

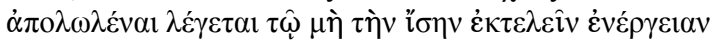

Para finalizar podemos ver algunos ejemplos con un sustantivo. En este caso lo esperable es que las expresiones estén integradas por el propio sustantivo y otro sustantivo en genitivo o bien un adjetivo. Nos servirá para la ejemplificación la palabra $\pi \rho \hat{\alpha} \xi 1 \varsigma$, bajo cuyo lema no deberían faltar, entre otras, las siguientes expresiones (criterios de búsqueda iguales a los de las palabras anteriores):

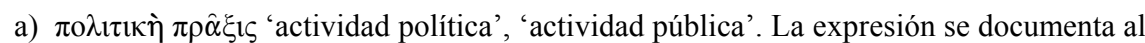
menos dieciocho veces en autores como Platón, Jenofonte, Aristóteles, Dionisio de Halicarnaso, Plutarco o Galeno.

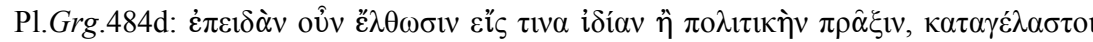

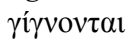

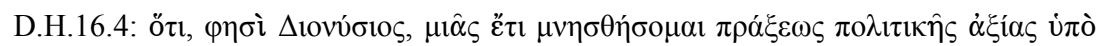
$\pi \alpha ́ v \tau \omega v \dot{\alpha} v \theta \rho \omega ́ \pi \omega v \dot{\varepsilon} \pi \alpha 1 v \varepsilon \hat{\sigma} \sigma \theta \alpha 1$

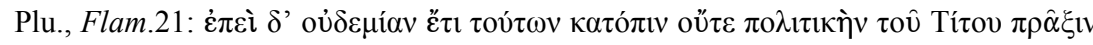

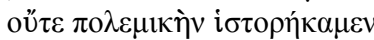

b) $\pi \mathrm{o} \lambda \varepsilon \mu 1 \kappa \eta े ~ \pi \rho \hat{\alpha} \xi 1 \varsigma$ 'actividad militar', 'acciones guerreras'. Esta expresión se documenta al menos doce veces, entre otros en Platón, Aristóteles, Diodoro de Sicilia y Plutarco.

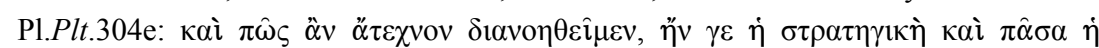

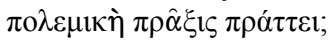

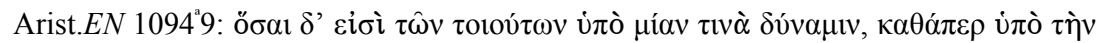

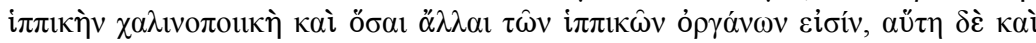

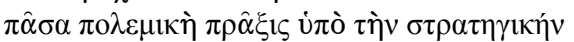




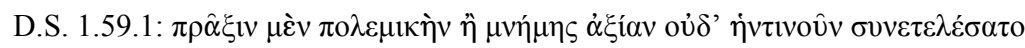

Pero en este "trabajo de campo" en lexicografía griega hay un tercer elemento fundamental que en absoluto se puede descuidar: el estudio de los propios textos. Aquí voy a detenerme a realizar un excurso para intentar mostrar las repercusiones que sobre la lexicografía griega tienen los avances en otras áreas de la Filología Griega y que obligan a que ésta se encuentre en permanente actualización y tenga que seguir de cerca los resultados alcanzados en ámbitos muy diversos. Voy a ocuparme de la Crítica Textual y Edición de Textos y dejo para otra ocasión la Sintaxis. La elección de estas dos áreas no es caprichosa ni debida al azar, sino que está en función de las tres fases de la investigación en lexicografía a las que aludía antes: la crítica textual y la edición de textos inciden fundamentalmente en el momento de recopilación de los materiales y la sintaxis en la de organización y presentación de los materiales.

3. Crítica textual y edición de textos y sus repercusiones en el trabajo en lexicografia

Analizaré a continuación algunos ejemplos concretos de las repercusiones que para el trabajo en lexicografía griega tienen los avances recientes en crítica textual y edición de textos. Los ejemplos podrían multiplicarse, pues, afortunadamente, el número de ediciones críticas publicadas en los últimos años es considerable, como lo muestra, sin ir más lejos, la renovación de ediciones que ha habido que hacer para el $D G E$ en los años transcurridos entre la publicación del volumen I y el volumen III y los suplementos necesarios para cada nuevo fascículo ${ }^{19}$. He elegido, por tanto, ediciones y textos que sirvan para ejemplificar casos y circunstancias diversas.

Uno de los textos literarios más importantes publicados en los últimos tiempos es el papiro de Estrasburgo 1665-1666, que contiene parte del libro I de la Física de Empédocles ${ }^{20}$. La identificación del texto y su atribución a Empédocles han sido posibles gracias a las coincidencias en algunos pasajes con fragmentos del poema conservados por la tradición indirecta. El texto ha supuesto un importante avance en el conocimiento del pensamiento de Empédocles y ha servido para dilucidar algunos problemas discutidos acerca

19 La lista actualizada de ediciones utilizadas en el $D G E$ puede consultarse en su página web (http://www.filol.csic.es/dge/lst/lst-int.htm).

20 A. Martin — O. Primavesi (eds.), L'Empédocle de Strasbourg (P.Strasb.gr. Inv. 16651666), Berlín y Nueva York, 1999. 
de su cosmología, pero ahora, dejando de lado cuestiones tan interesantes como ésas, me centraré en sus aportaciones a la lexicografía general del griego antiguo. Para ello he analizado en detalle el texto del papiro y creo que las aportaciones más significativas se refieren a las palabras que analizaré a continuación. Comenzaré en primer lugar por los hapax, de los que el papiro aporta dos concretamente:

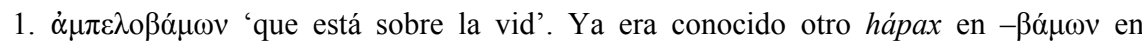

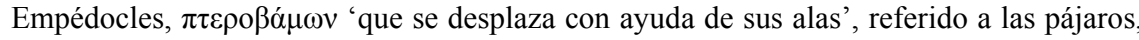
que es, precisamente, el texto para el que ahora tenemos el testimonio del verso c8 del papiro de Estrasburgo. Otros compuestos en $-\beta \alpha ́ \mu \omega v$ aparecen en la tragedia, donde nos

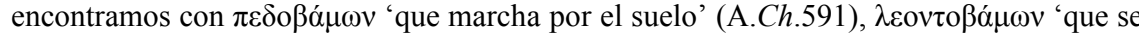

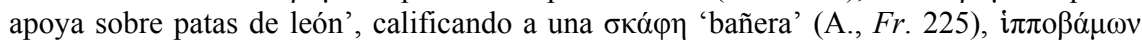

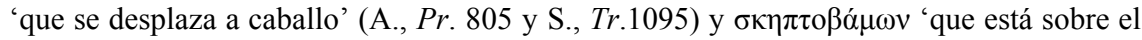
cetro', dicho del águila de Zeus (S., Fr. 884). El papiro está roto justo detrás de $\dot{\alpha} \mu \pi \varepsilon \lambda \mathrm{o} \beta \alpha[$, por lo que no sabemos a qué sustantivo calificaba. Los editores restituyen

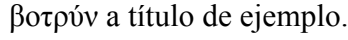

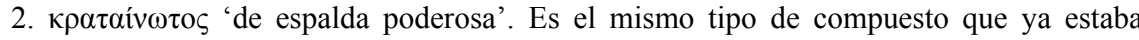
atestiguado en otro hápax empedocleo, $\beta \alpha \rho v ́ v \omega \tau o \varsigma$ 'de espalda pesada', referido a las conchas marinas. Los compuestos en $\kappa \rho \alpha \tau \alpha l-$ aparecen ya en los poemas homéricos

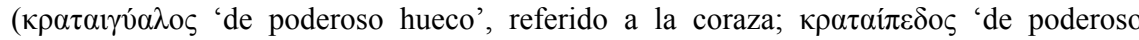

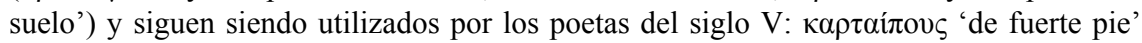

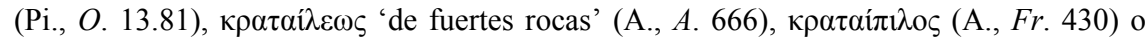

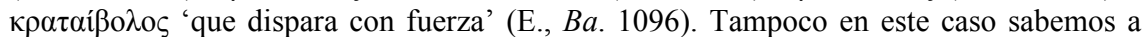
qué sustantivo calificaba este adjetivo, pues el papiro está roto justo detrás.

En cuanto a las palabras de baja frecuencia que ahora amplían su testimonio, tenemos:

1. $\dot{\alpha} \varepsilon \kappa \alpha \zeta$ ó $\mu \varepsilon v o \varsigma$ 'contra su voluntad'. Esta palabra únicamente estaba atestiguada en $\mathrm{Il}$. 6.458, Od. 13.277, 18.135 e h.Cer. 30, 432, aparte de en los escolios, comentaristas de Homero y gramáticos. Aquí se refiere a los "miembros", dentro de la teoría general de Empédocles sobre la formación de los cuerpos de los humanos y los animales.

2. ¿̋ $v \delta \imath \alpha \alpha$ 'separadamente'. En la literatura anterior a Empédocles la palabra sólo está atestiguada en unos cuantos pasajes homéricos, en Hesíodo y en el épico Eumelo. También aparece en poetas posteriores y otra vez en el propio Empédocles (B 21).

3. $\delta \dot{\alpha} \pi \tau v \xi 1 \varsigma$ 'despliegue'. Aparte de unas pocas apariciones en la literatura griega con el sentido, en la esfera de la lengua, de 'desarrollo, explicación', el único ejemplo con el sentido de 'despliegue, acción de desplegar' se encontraba en Procl., Hyp. 5.110.

4. ópí $\pi \lambda \alpha \gamma \kappa \tau o \varsigma$ 'que vaga por el monte'. La palabra, referida en el papiro a $\theta \hat{\eta} \rho \varepsilon \varsigma$, estaba atestiguada sólo tres veces en la literatura griega: Ar., Th. 326, Opp., C. 3.224, Nonn., D. 21.189. Para el primer término de compuesto los manuscritos de esos autores vacilan entre el diptongo -Et- e -1-.

5. $\chi \eta \lambda \eta$ ' 'garra'. Los editores del papiro defienden que se trata de un uso derivado a partir del sentido 'pinzas' del cangrejo con que aparece en varios pasajes de Aristóteles ( $H A$ $527^{\mathrm{b}} 5, P A 684^{\mathrm{a}} 27$, etc.) y que sirve también de nombre para la constelación de Libra, 
entendida como las "pinzas" del Escorpión (Arat.89, 232, etc., Ptol.Tetr.24, etc.). Éste es, además, un caso muy interesante, pues, en realidad, lo conservado en el papiro es lo

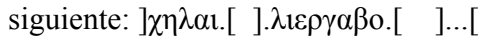

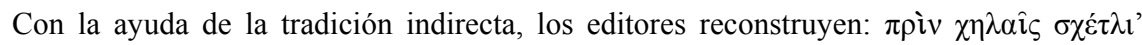

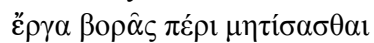

El texto conocido anteriormente, conservado por Porfirio (Abst.2.31.4-5 = Emp.B 139) es:

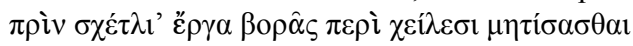

En principio, tendríamos la tentación de suponer que $\chi \varepsilon \dot{\varepsilon} \lambda \varepsilon \sigma \mathrm{l}$ 'con sus labios', metonímico para designar a la boca, es más adecuado que el $\chi \eta \lambda \alpha \hat{\imath} \varsigma$ del nuevo papiro y que la lectura del papiro se explica por itacismo y por lectura del diptongo - $\alpha$ - como /e/. Sin embargo, he escrutado el papiro a la búsqueda de algún caso de itacismo y no los hay, por lo que más bien hay que pensar que la confusión fonética y la banalización del texto se han producido en la transmisión indirecta, de modo que la palabra $\chi \varepsilon i ̂ \lambda o \varsigma$ 'labio' no se puede atribuir a Empédocles.

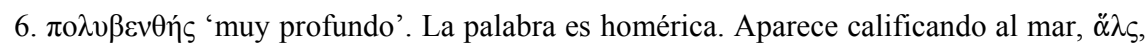
en $O d .4 .406$ y referida a un puerto en $I l .1 .432$ y $O d .10 .125,16.325$. También es usada por A.R. 4.599. En el papiro de Empédocles el texto está perdido a partir de la - $\theta$ - de esta palabra, por lo que no sabemos a qué sustantivo calificaba, aunque seguramente se tratara de $\Delta \hat{\mathbf{i} v o \zeta, ~ c o m o ~ s u g i e r e n ~ l o s ~ e d i t o r e s . ~}$

7. $\pi \circ \lambda v \pi \eta$ $\mu \omega v$ 'muy doloroso'. En el texto de Empédocles califica a $\kappa \rho \hat{\alpha} \sigma \iota \varsigma$, en referencia al dolor que causa la mezcla que lleva al Torbellino de la destrucción. Hasta el momento los únicos testimonios antiguos de la palabra se encontraban en los Himnos Homéricos (h.Cer. 230, h.Merc. 37). Los editores interpretan el adjetivo en sentido pasivo, 'mezcla sujeta a muchos dolores', pero este sentido pasivo del adjetivo no es antiguo ni frecuente. De hecho, sólo se atestigua en Manilio $(1.8 .5,4.49)$, por lo que es preferible entender el adjetivo en el texto de Empédocles en su sentido más habitual.

8. $\varphi v \tau \alpha ́ \lambda \mu 10 \varsigma$ 'que produce, que cría'. Aparte de testimonios epigráficos como epíteto de dioses, este adjetivo aparece varias veces en el drama clásico referido a "padres"

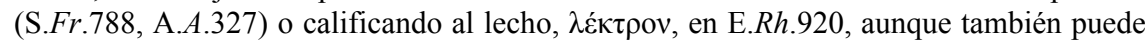
tener el significado de 'congénito', 'nacido así', como en S., OC 150, en referencia a que su ceguera no lo es.

Por último, también resultan muy interesantes otras dos palabras para las que este papiro de Estrasburgo nos atestigua nuevos significados. Se trata de:

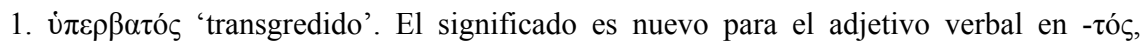
aunque ya estaba atestiguado en el verbo i் $\pi \varepsilon \rho \beta \alpha i v \omega$ (Heraclit. 94, Pi., Fr. 1.5, Hdt. 3.83, S., Ant. 449 , etc.). En el texto de Empédocles se aplica a $\beta \varepsilon ́ v \theta \varepsilon \alpha$, en referencia, según señalan los editores, al momento en que predomina la Discordia y se adentra incluso en el pequeño reducto reservado al Amor, aunque el significado que ellos proponen no es exactamente éste, pues lo interpretan como 'ocupar de manera delictiva', 'penetrar ilegalmente y con violencia', en relación con algún pasaje clásico (E., Med.381-383), en que el verbo í $\pi \varepsilon \rho \beta \alpha i v \omega$ tiene ese sentido. No me parece que esa intepretación tan específica se pueda deducir del contexto en el caso del texto de Empédocles.

2. $\varphi \hat{v} \mu \alpha$ 'descendencia, prole'. La palabra estaba atestiguada en un pasaje de Areteo (Aret., $S D$ 2.13) en el sentido de 'crecimiento' ('̇ं $\varphi \hat{v} \mu \alpha \zeta \omega \eta \hat{\zeta})$ ), pero lo más habitual es que se refiera a "algo que crece" y, específicamente, su uso más extendido es en medicina 
con el sentido de 'tumor, excrecencia'.

Parece natural que las nuevas publicaciones de textos literarios conservados en papiros aporten nuevos materiales de interés para el trabajo en lexicografía. Sin embargo, la repercusión de las nuevas ediciones de textos sobre la investigación en lexicografía no se limita únicamente a casos como éste. Incluso textos tantas veces editados y cuyo estudio podemos decir sin exageración que supuso la fundación de los estudios filológicos - me refiero, claro está, a los poemas homéricos - cuando se revisan críticamente y se elaboran nuevas ediciones, para las que ahora pueden tenerse en cuenta, además de manuscritos adicionales a los utilizados en la editio maior de Allen, también un número importante de papiros que conservan parcialmente su texto, aportan materiales que un diccionario general de griego debe, necesariamente, tener en cuenta. Ciñéndome ahora a la Iliada, la aparición de dos nuevas ediciones, una de ellas todavía en curso de publicación, tiene consecuencias directas para la lexicografía. Las ediciones a las que aludo son la bilingüe de José García Blanco y Luis Macía ${ }^{21}$, que llega de momento hasta el canto IX, y la teubneriana de Martin L. West ${ }^{22}$. El número de papiros que conservan partes de la Iliada alcanza actualmente casi el número de seiscientos cincuenta ${ }^{23}$. La edición española supone, además, la incorporación al corpus de manuscritos manejados para el establecimiento del texto de varios ejemplares de los monasterios del monte Athos no manejados por Allen.

He procedido a realizar una colación completa para el libro I de la Iliada de las ediciones de García Blanco y Macía y de West entre sí y con el texto oxoniense de Allen como aproximación sistemática a las repercusiones que para la investigación en lexicografía homérica y lexicografía general del griego antiguo suponen estas nuevas ediciones. Fundamentalmente habría que señalar las siguientes divergencias:

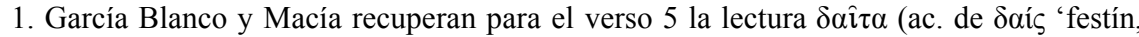
banquete'), frente al dat. $\pi \hat{\alpha} \sigma ı v$ que imprimía la edición de Allen. $\Delta \alpha \hat{\imath} \tau \alpha$ es lectura zenodotea según el testimonio de Ateneo (I 12e) frente al $\pi \hat{\alpha} \sigma ı v$ de los códices. La elección entre una y otra variante ha dividido a la crítica moderna. La primera tiene a su favor ser la lectio difficilior frente a un banal $\pi \hat{\alpha} \sigma v$. De aceptarse supondría añadir un segundo testimonio homérico a $\delta \alpha i$ ç referido al alimento de animales, que aparece en $I l$. XXIV 43 (v. $D G E$ 反aí II).

21 Homero, Iliada, ed. y trad. de J. García Blanco y L. Macía, Madrid, 1991 y 1998.

22 Homerus, Ilias, ed. de Martin L. West, 2 vols., Stuttgart y Leipzig, 1998-2000.

23 Véase L. Macía, «Lista de papiros para una edición de la Iliada», Tempus 19, 1998, pp. 5-57, así como las pp. XXXVIII-LIV de la edición de West. 


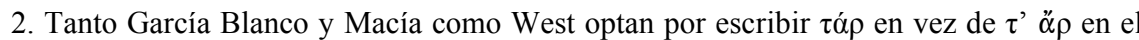
v. 8 y en otros lugares, siguiendo las indicaciones de Herodiano y Apolonio Díscolo. De

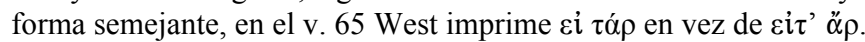

3. En el verso 59 García Blanco y Macía y West imprimen $\pi \alpha ́ \lambda ı ~ \pi \lambda \alpha \gamma \chi \theta \varepsilon ́ v \tau \alpha \varsigma$, esto es, dos palabras, frente a $\pi \alpha \lambda \mu \mu \pi \lambda \alpha \gamma \chi \theta \varepsilon ́ v \tau \alpha \varsigma$ de la edición de Allen, que hacía lo mismo en Od. XIII 5, siguiendo a casi todos los códices. Esto suponía la necesidad de incluir en los diccionarios de griego un lema $\pi \alpha \lambda \iota \mu \pi \lambda \alpha \dot{\zeta}$ o $\mu \alpha$ ' 'estar errante de nuevo', si bien ya en el Lidell-Scott-Jones se indicaba que era preferible leer la secuencia como dos palabras separadas, a pesar de la discusión suscitada ya en la antigüedad, según muestra el $E M$ s.u. Las nuevas ediciones implican, por tanto, eliminar este lema y citar, en todo caso, estos pasajes en el lema $\pi \lambda \alpha \dot{\zeta} \omega$.

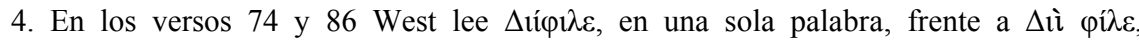
transmitido por los códices. La primera lectura aparece en muchos autores antiguos (v. $D G E$, s.u. $\Delta$ í $\varphi(\lambda \circ \varsigma)$, por lo que tampoco carece de autoridad.

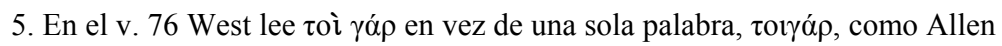

6. En Il. I 97 la lectura aristarquea, aceptada por Allen, era: oủ ' ö $\gamma \varepsilon \pi \rho i ̀ v ~ \Delta \alpha v \alpha o i ̂ \sigma ı v$

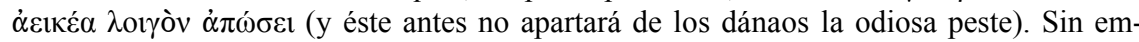
bargo, la lectura que ofrecen los papiros para este verso, que coincide en este caso con la vulgata de los códices medievales y el texto de Zenódoto y que aceptan tanto la edición

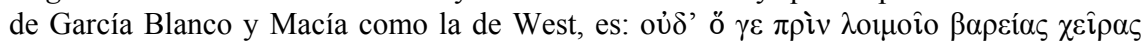

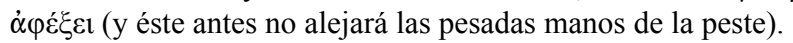

Para la lexicografía esto supone, por un lado, cuestionar y limitarse a citar en todo caso como variante, una de las apariciones en la épica homérica del adjetivo ảєıкńs, que no es palabra excesivamente documentada en la literatura griega. Por otro, incorporar un

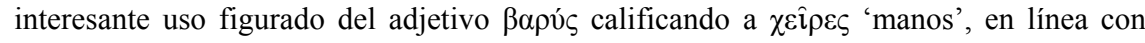

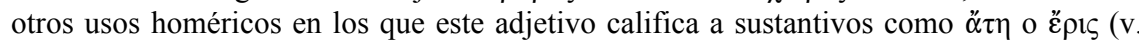
$D G E, \beta \alpha \rho v ́ \varsigma$ B II 1). Y, además, la utilización figurada del sintagma $\chi \varepsilon \hat{\imath} \rho \alpha \varsigma \dot{\alpha} \varphi \varepsilon ́ \xi \varepsilon ı v$, que

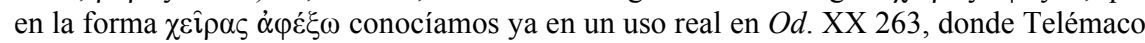
se refiere a la protección que otorgará a Odiseo, disfrazado aún de mendigo, frente a los pretendientes.

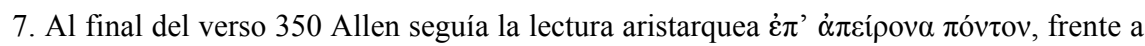

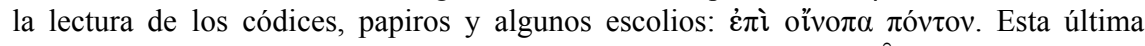
lectura permite añadir un ejemplo más de la utilización del adjetivo oỉvo $\psi$ referido al mar, como en Il. XXIII 316 y Od. II 421 y V 132.

8. Aunque se trata de palabras sinónimas y métricamente equivalentes conviene señalar la

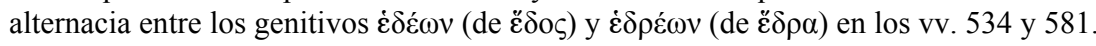

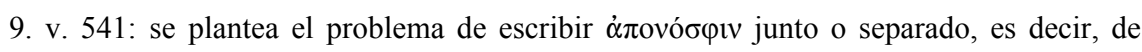

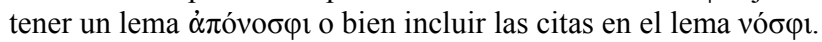

10. En el v. 562 ni García Blanco y Macía ni West aceptan la lectura del papiro PColumb.8.197 que tiene $\dot{\varepsilon} \kappa$ en vez de $\dot{\alpha} \pi$ é en la secuencia $\dot{\alpha} \pi$ ò $\theta 0 \mu \mathrm{o} \hat{u} \mu \hat{\alpha} \lambda \lambda$ ov $\dot{\varepsilon} \mu \mathrm{o}$

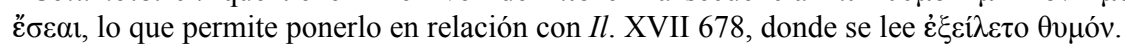

Sin embargo, la aparición de nuevas ediciones no supone necesariamente un avance, desde el punto de vista de la lexicografía, en relación con todas las palabras del texto editado y, como ya ha quedado implícito en las consi- 
deraciones expuestas, para que la investigación en lexicografía se desarrolle con paso firme ha de hacerse una utilización crítica de las ediciones críticas. Podríamos multiplicar los ejemplos, pero me ceñiré ahora a algunos de los que se plantean en el texto de los trágicos, concretamente en el de Esquilo y de Eurípides, y a las recientes ediciones teubneriana y oxoniense a cargo, respectivamente, de Martin L. West y J. Diggle ${ }^{24}$.

En la edición de West de las tragedias de Esquilo, publicada por Teubner en Stuttgart en 1990, nos encontramos con problemas como los siguientes, a los que me he ido enfrentando durante el proceso de revisión del volumen VI del $D G E$ :

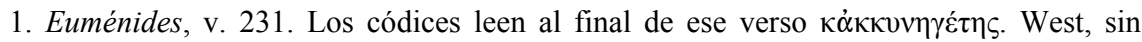
embargo, acepta una corrección de Powell basada en el $\dot{\varepsilon} \kappa \kappa v v \eta \gamma \dot{\varepsilon} \sigma \alpha \iota$ que encontramos en

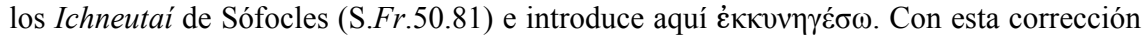
la lectura e interpretación de los vv. 230-231 serían:

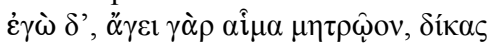

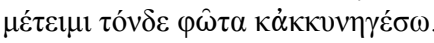

Pero yo, puesto que me guía la sangre de su madre, para hacer justicia voy tras este hombre y le daré caza.

Así pues, desde el punto de vista lexicográfico, de aceptar esta corrección tendríamos una

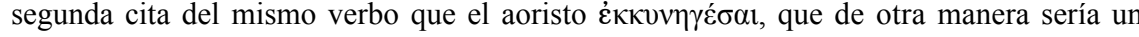

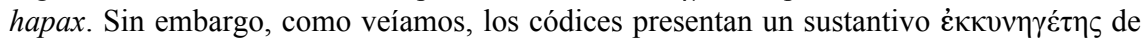
impecable formación, que, de aceptarse acríticamente la lectura de la edición de West, quedaría excluido de los léxicos. En realidad, la necesidad de encontrar un verbo en la

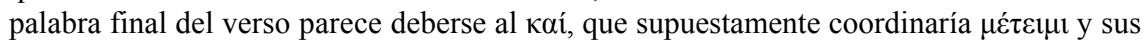
complementos, por un lado, y, por otro, este segundo verbo, que llevaría también

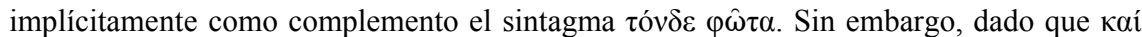
no necesariamente tiene que ser coordinativo, sino que puede utilizarse con los sentidos de "también" o "incluso", la palabra que en los códices cierra el verso 231 es perfectamente comprensible y defendible en el contexto. Manteniéndola, la interpretación de los vv. 230-231 de Euménides sería: "Pero yo, puesto que me guía la sangre de su madre, para hacer justicia voy tras este hombre convertida en cazadora." Así pues, a pesar de la ausencia de la palabra en la edición que en estos momentos es la edición de

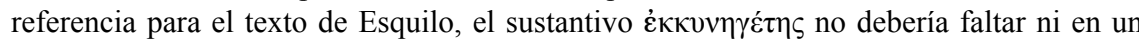
léxico de Esquilo ni en un diccionario general del griego.

2. En otras ocasiones la intervención del editor puede afectar no a la clase morfológica a la que pertenece la palabra, como era el caso del ejemplo anterior, sino a su forma y a su

24 Véanse, a propósito de la introducción de correcciones y conjeturas innecesarias en el texto de Eurípides y de la inadecuada homogeneización de los textos, los artículos de F. R. Adrados, «Notas críticas a Eurípides, Medea», Emerita 61, 1993, pp. 241-266; "Volvamos al léxico y la sintaxis de los manuscritos. A propósito de Eurípides, Medea y Cíclope», en: Actas del IX Congreso Español de Estudios Clásicos, Madrid, 1998, pp. 317-322; «Notas críticas a Eurípides, Cíclope», en: U. Criscuolo — R. Maisano (eds.), Synodia. Studia humanitatis Antonio Garzya septuagenario ab amicis atque discipulis dicata, Nápoles, 1998, pp. 13-21. 
composición. Tomemos otro ejemplo de las Euménides, en este caso el v. 113. Aquí es el espectro de Clitemnestra el que está hablando, en una de las escasísimas intervenciones de fantasmas en el teatro griego, para instar a actuar a las Euménides y vengar el crimen cometido contra ella por su hijo Orestes. El final del v. 113 es, según el texto de West:

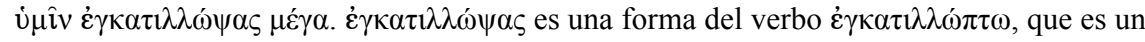
hapax. El verbo simple, $\kappa \alpha \tau \imath \lambda \lambda \omega ́ \pi \tau \omega$ no es que sea muy frecuente, pero sí que se lee un par de veces en los textos griegos conservados, concretamente en un fragmento del cómico Filemón y en $A P$ 5.200, aparte de en los lexicógrafos. En la Antología Palatina el verbo está en uso absoluto, sin complemento, pero, en cambio, en el fragmento de Filemón (Philemo 115) transmitido por Clemente de Alejandría (Paed.3.73.1) lleva un

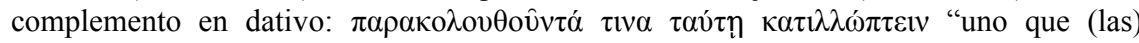
seguía y miraba maliciosamente a ésta (la esclava)". El sentido del verbo que pronuncia Clitemnestra, en función del contexto y del significado del verbo simple, no ofrece dudas; significa 'burlarse'.

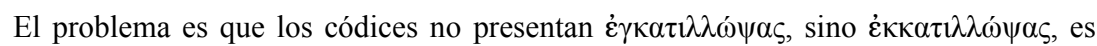
decir, un compuesto con $\dot{\varepsilon} \kappa-$ en vez de $\dot{\varepsilon} \gamma-$. Comencemos por señalar que las confusiones entre los compuestos con estos dos prefijos son frecuentes tanto en los manuscritos medievales como en los papiros e inscripciones, por lo que nada tendría de extraño que aquí tuviéramos un caso de ella. Sin embargo, creo que hay razones que hacen innecesaria la corrección de Turnebus en su edición parisina de 1552, aceptada por West. En efecto, la única justificación que habría para tal corrección es que parece más natural que sea un compuesto con $\dot{\varepsilon} \gamma$ - el que lleve un complemento en dativo, $\dot{v} \mu \hat{\imath} v$, como sucede con mucha frecuencia con los verbos formados mediante el preverbio $\dot{\varepsilon} v-$. Sin embargo, creo que tal corrección es abusiva frente a la lectura de los códices, غ̇к-, ya que el propio

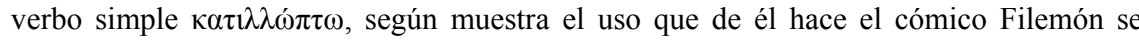
construye con dativo, por lo que tampoco hay nada de extraño en que se construya también con dativo de la persona que es objeto de la burla su compuesto con غ̇к-, un preverbio غ̇к- que, además, recordémoslo, no necesariamente es separativo, sino que con tanta o más frecuencia añade al verbo simple la idea de perfectividad, de acción realizada hasta el final o por completo, como parece ser el caso. En efecto, Clitemnestra reprocha a las Euménides que Orestes se está burlando completamente de ellas. Así pues, nuevamente parece que no hay que conformarse con el texto editado, sino que el lexicógrafo debe recoger el texto de los códices.

Para finalizar estas consideraciones me detendré en otro caso llamativo con el que nos encontramos en el último volumen de las tragedias de Eurípides de la edición oxoniense de Diggle, aparecido en 1994 y que contiene el texto de Helena, Fenicias, Orestes, Bacantes, Ifigenia en Áulide y el Reso. En el v. 1368 de Ifigenia en Áulide está hablando Ifigenia y dice, según el códice L (Laurentianus plut. 32.2, de principios del siglo XIV), que es testimonio único para el texto de esta tragedia de Eurípides:

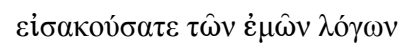

Que Diggle ha transformado en:

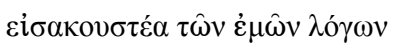


Se podría argumentar quizá que la corrección del editor tiene a su favor paleográficamente el hecho de que no necesita añadir ni eliminar letras, sino tan solo realizar una transposición de la $\alpha$ al final de la palabra. Sin embargo, introduce así un hapax, innecesariamente a mi juicio. Ninguna forma del

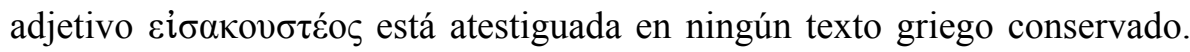
Pero es que, además, la corrección parece a todas luces innecesaria. El texto

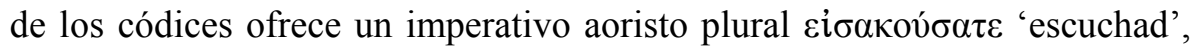
cuya única particularidad reside en que está dirigido a una sola persona, Clitemnestra. Sin embargo, esto dista mucho de ser un caso único y sin paralelos en la tragedia clásica, donde esta utilización del plural por singular es frecuente. Así, Stockert, autor de una edición con traducción y comentario detallado de esta tragedia ${ }^{25}$, publicada en 1992 (y que, por tanto, Diggle hubiera debido conocer, ya que el tercer volumen de sus tragedias de Eurípides es del año 1994), señala paralelos meridianos como S.OC 1104, donde se lee: $\pi \rho 0 \sigma \varepsilon ́ \lambda \theta \varepsilon \tau$ ', $\hat{\omega} \pi \alpha \hat{\imath}, \pi \alpha \tau \rho i ́$. Por otra parte, ¿cómo debemos

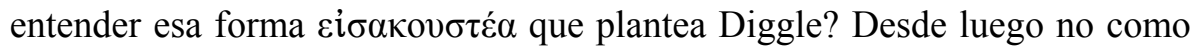
femenino referido a Clitemnestra, puesto que ya existe un complemento en genitivo regido por ese verbo, $\tau \hat{\omega} v \dot{\varepsilon} \mu \hat{\omega} v \lambda{ }^{\prime} \gamma \omega v$. Habría que pensar, entonces, que nos encontramos ante el neutro plural usado en forma impersonal, es decir, intepretar el texto como: "madre, hay que prestar atención a mis palabras". El neutro plural en - $\tau \dot{\varepsilon} \alpha$ puede utilizarse en la lengua clásica en esta función, pero no deja de ser una rareza frente a las formas en $-\tau \varepsilon \dot{o v}$, que son las que aparecen habitualmente. En definitiva, la conjetura del editor introduce un hapax, implica entender una construcción enrevesada y da un sentido peor que el texto de los códices en el contexto de la tragedia, donde la apelación directa de Ifigenia a su madre a través del imperativo y no de un impersonal es más comprensible y viene, además, corroborada por el vocativo $\mu \hat{\eta} \tau \varepsilon \rho$ que le precede. Así pues, nos encontramos con un caso en que el lexicógrafo ha de plantearse si incluir o no en su diccionario una palabra que, en realidad, es creación de un editor moderno y que esperemos que posteriores ediciones de Eurípides eliminen del texto.

Los ejemplos mostrados creo que bastan para hacer ver cómo el lexicógrafo en su investigación no puede hacer un uso ciego de los textos clásicos, sino que, aparte de la necesaria selección de ediciones canónicas que caracteriza a la lexicografía moderna y que son la referencia precisa para

25 Walter Stockert (ed.), Euripides. Iphigenie in Aulis, 2 vols., Viena, 1992. 
la constitución del corpus sobre el que desarrollar la investigación, el lexicógrafo no tiene más remedio que estar atento y seguir el progreso de la investigación en crítica textual y edición de textos para hacer un uso adecuado de las ediciones que no le lleve a excluir palabras bien formadas y que cuentan con el apoyo de la tradición manuscrita frente a las arbitrariedades en que pueda incurrir un editor en un pasaje determinado.

\section{Fases de organización y presentación de los materiales}

Retomo ahora el hilo conductor relativo a las diferentes fases de elaboración de un diccionario y paso a ocuparme de la organización y presentación de materiales porque, aunque conceptualmente la distinción es clara y a nivel teórico conviene diferenciarlas, en la práctica lexicográfica, en la redacción de artículos, lo habitual es que se aborden de forma conjunta.

La organización y presentación de las traducciones, citas y referencias que se incluyen en un artículo exigen un esfuerzo de sistematización y formalización que permitan, por un lado, que la distribución de los diferentes apartados sea lingüísticamente correcta y coherente $\mathrm{y}$, por otro, que el usuario del diccionario pueda encontrar de forma fácil y rápida la información que le interesa.

Con todo, los recientes debates y propuestas en lexicografía general han apuntado una serie de problemas que, en mi opinión, resulta también necesario plantearse para el caso de la lexicografía griega y que pueden traducirse en un refinamiento aún mayor de los métodos a la hora de seleccionar y organizar los materiales que se incluyen en cada artículo concreto. Repasaré a continuación algunas de estas cuestiones.

Necesariamente en un diccionario bilingüe como el $D G E$ uno de los aspectos fundamentales lo constituyen las traducciones que se ofrecen en la lengua de salida, el español, de las palabras de la lengua de entrada, el griego antiguo. El problema que se le plantea al redactor de un artículo es que a la hora de ofrecer una traducción ha de tomar posición entre dos tendencias contrapuestas: ofrecer una explicación del significado de la palabra, de gran poder explicativo, pero que no resulta directamente utilizable en la traducción de un texto, o bien, ofrecer una traducción utilizable directamente en contexto pero cuyo poder de explicación siempre será más bajo ${ }^{26}$. La

26 Véase D. M. T. Farina, «The bilingual lexicographer's best friends», Lexicographica 12, 1996, pp. 1-15. También son muy útiles a este respecto las reflexiones y observaciones que 
combinación de estos dos extremos nos permite establecer una escala de gradación entre cuatro términos:

1. equivalente de traducción (directamente insertable en la traducción, bajo poder explicativo),

2. equivalente de traducción ideal (directamente insertable, alto poder explicativo),

3. equivalente explicativo (poco insertable),

4. explicación de significado (nada insertable).

Salvo los afortunados casos en que se encuentra un equivalente de traducción ideal, es decir, en el caso específico de un diccionario griego-español, un equivalente español de una palabra griega que se puede utilizar directamente en una traducción y que, además, permita comprender el alcance semántico del término griego, el redactor de un lema del diccionario debe decidir normalmente entre ofrecer un equivalente de traducción, con lo que pierde en poder de explicación, o bien ofrecer un equivalente explicativo, que no resulta directamente utilizable. La reciente experiencia de la redacción de los compuestos de $\delta v \sigma-$, que aparecerán en el volumen VI del $D G E$, ha puesto de manifiesto bien a las claras este problema. En bastantes de esos compuestos, si se hubiera optado por un equivalente de traducción, es decir, una palabra directamente utilizable en la traducción de un texto griego al español se hubiera caído con frecuencia en un general y vago "difícil, dificultoso". Para precisar más, en cambio, ha habido que recurrir a una explicación que no resultaba ya directamente utilizable en la traducción seguida de un texto.

Antes de pronunciarme a favor de una u otra solución y de ofrecer alguna propuesta, conviene recordar cuáles son los posibles objetivos del usuario de un diccionario bilingüe de griego antiguo ${ }^{27}$ :

1. El primero, lógicamente, es buscar una palabra desconocida en griego o un significado desconocido de una palabra.

2. Pero no debemos olvidar que un usuario de un diccionario bilingüe también recurre a él para buscar la mejor forma de expresar en español una palabra griega conocida. Este segundo aspecto es importante porque obliga a plantearse algo más que el "significado" de una palabra, dado que la

aparecen en V. Schnorr, «Translational equivalent and/or explanation? The perennial problem of equivalence», Lexicographica 2, 1986, pp. 53-60.

27 He adaptado al caso concreto del griego antiguo las observaciones que a propósito de los diccionarios bilingües inglés-francés hace A. Duval, «La métalangue dans les dictionnaires bilingues», Lexicographica 2, 1986, pp. 93-100, así como las reflexiones de Farina en el artículo citado en $n$. anterior. 
redacción final de un artículo del diccionario ha de permitir al usuario realizar las asociaciones y transformaciones necesarias entre las dos lenguas para conseguir su objetivo, a lo que han de contribuir también los ejemplos y las traducciones de los ejemplos que en él se recojan.

En este sentido, creo que se puede intentar un equilibro entre los polos "equivalente de traducción" (poco explicativo pero directamente insertable) y "equivalente explicativo" (poco insertable) ofreciendo en cabeza del artículo el equivalente explicativo e incluyendo ejemplos traducidos en el cuerpo del artículo donde se utilice el equivalente de traducción, con lo que el usuario tiene acceso al mismo tiempo a los dos tipos de informaciones que puede necesitar y para las que recurre al diccionario: la explicación de un término que desconoce y la palabra castellana que puede utilizar para realizar una traducción. Así, por ejemplo, el sentido general frecuente de $\delta v ́ v \omega$ como verbo de movimiento intransitivo es 'penetrar en', 'adentrarse en', 'introducirse en'. Sin embargo, si se incluye bajo ese lema la cita $\tau$ ì

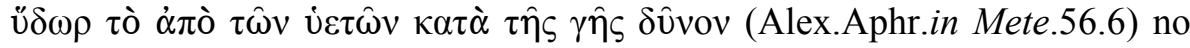
está de más ofrecer la traducción contextual "el agua de lluvias que se filtra en la tierra" para ofrecer al posible usuario el más matizado 'filtrarse'

En relación con esta cuestión paso a ocuparme de los "problemas de ejemplificación en los diccionarios bilingües", tema sobre el que ha habido bastante bibliografía en los últimos tiempos ${ }^{28}$. Naturalmente, los problemas que hay que abordar a la hora de seleccionar las citas en un diccionario general de griego antiguo no son exactamente los mismos que en el caso de una lengua moderna, de entrada porque aquí no se plantea el debate sobre si los ejemplos pueden ser creación del propio lexicógrafo o éste ha de tomar siempre sus ejemplos de otras fuentes. En la lexicografía del griego antiguo, además, existen una serie de autores, como pueden ser Homero, Hesiodo, los líricos arcaicos, los trágicos, Platón, Aristófanes, Hipócrates o Aristóteles, entre otros, a los que, debido a la propia tradición de estudio que arranca de la Antigüedad y a la importancia de estos autores dentro de la literatura y la cultura griega, es obligado citar dentro de un lema si la palabra en cuestión ha sido utilizada por ellos. Con todo, sí que existen problemas similares a los que ha de afrontar la lexicografía de las lenguas modernas a medida que

28 De los trabajos recientes el fundamental es el de T. Szende, «Problems of exemplification in bilingual dictionnaries», Lexicographica 15, 1999, pp. 198-228. Hay también ideas interesantes en J. L Orduña, «La función definitoria de los ejemplos: a propósito del léxico filosófico del Diccionario de Autoridades», en: Así son los diccionarios, Lérida, 1999, pp. 99119, esp. pp. 103-105. 
aumenta la frecuencia de aparición de una palabra en la literatura griega antigua, pues de las múltiples apariciones que puede haber de una palabra dentro del mismo autor hay que seleccionar cuál o cuáles se citan y de cuáles se ofrece el contexto. $\mathrm{Y}$ de forma similar hay que proceder a la hora de decidir entre las citas de unos y otros autores. Para seleccionar los ejemplos se pueden manejar, por tanto, criterios similares a los que se emplean en los diccionarios de lenguas modernas, como son los siguientes. Los ejemplos deberían servir para:

a) dar al lector frases en las que el significado de la palabra quede más claro por

el contexto;

b) mostrar la palabra utilizada en su contexto;

c) recordar al lector la existencia de locuciones y clichés.

Es decir, la selección de citas debe cumplir dos funciones principales: ejemplificación y desambiguación semántica. Los tres principios citados, además, se pueden subsumir bajo un planteamiento general, pues, como señala Szende ${ }^{29}$, los ejemplos nunca deben ser gratuitos ni un mero adorno, sino que deben incluir información complementaria.

Cumplir el tercero de los objetivos a los que acabo de aludir, es decir, ocuparse de las locuciones y clichés dentro del artículo, supone importantes dificultades a la hora de su tratamiento lexicográfico, que se agravan en el caso del griego antiguo dado que, claro está, no tenemos hablantes cuya conciencia permita distinguir qué es un cliché y qué no. Messelaar, en un interesante libro titulado La confection du dictionnaire général bilingue ${ }^{30}$, plantea cuatro criterios para decidir qué unidades superiores a la palabra deben incorporarse dentro de un lema:

a) La existencia de oposiciones interlingüísticas a la hora de producir enunciados sinónimos, como puede ser, por ejemplo, la presencia de términos que no se esperarían desde un punto de vista lógico pero que, sin embargo, se ven favorecidos por el uso. Esto implica, para un diccionario general de griego, la necesidad de recoger clichés del tipo $\kappa \alpha \lambda$ ò $\varsigma \alpha \grave{~} \alpha \gamma \alpha \theta$ ós, cuyo significado no se puede obtener meramente combinando los significados de las dos palabras coordinadas "bello" + "bueno", sino que requiere a la hora de traducir recurrir a expresiones como "una persona de bien", "una bella persona" o, como aparece en el LSJ, "a perfect gentleman". Un caso especial es el de las paremias, puesto que lo más frecuente es que para expresar una misma idea se recurra a términos y expresiones diferentes en la lengua de entrada y de salida. Así, una expresión como

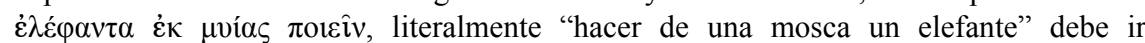

29 Art. cit. en n. anterior, p. 225.

30 P. A. Messelaar, La confection du dictionnaire général bilingue, Lovaina, 1990. 
acompañada también de su equivalente en español, o sea, "hacer un castillo de un grano de arena".

b) La identidad de las construcciones en ambas lenguas (la de entrada y la de salida) y la limitación en el número de combinaciones que son posibles lógicamente. Así, aunque no

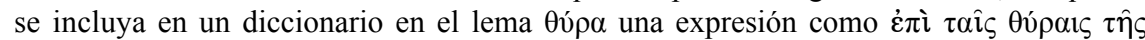
'E $\lambda \lambda \alpha \dot{\alpha} \delta \mathrm{o} \zeta \dot{\varepsilon} \sigma \mu \varepsilon \dot{v}(\mathrm{X} . A n .6 .5 .23)$ no se dificultará su traducción e interpretación puesto que en español "estar a las puertas de" tiene el mismo sentido.

c) El hecho de que la palabra clave de la locución o cliché no se pueda traducir de algunas de las formas que se dan en el encabezamiento del artículo. Así, sucede con frecuencia que la utilización de un acusativo interno con juego etimológico en griego implica la necesidad de variar la traducción del verbo al español aunque el sentido siga siendo el mismo, por lo que resultará conveniente incluir la expresión acompañada de su traducción. Por ejemplo, como traducción general del verbo voбéc, y dejando ahora de lado los usos figurados, habrá que ofrecer "estar enfermo", pero en el caso de vóбov voб\&îv habrá que especificar como traducción "sufrir una enfermedad", "padecer una enfermedad", puesto que la expresión "estar enfermo de una enfermedad", aunque sería posible en español, no es la habitual.

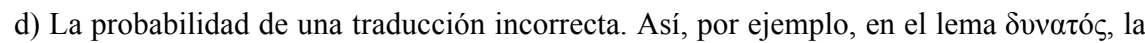

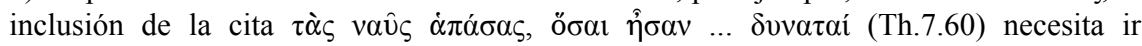
acompañada de la traducción "todas las naves que estaban en estado de uso", puesto que el sentido general bajo el que se ha de subsumir la cita es el 'fuerte', 'resistente', sentido que tiene el adjetivo cuando va referido a cosas.

Así pues, estos criterios resultan válidos para seleccionar qué locuciones y clichés se incluyen y cuáles no, pero, como señalaba, en el caso del griego seguiríamos teniendo el problema de qué métodos y criterios podemos utilizar para identificar esos clichés. Sin embargo, en $\S 2$ ya expusimos cómo se puede intentar solventar este problema ${ }^{31}$.

\section{Conclusión}

A lo largo de este trabajo he intentado realizar algunas propuestas que contribuyan a mejorar el trabajo en lexicografía griega a partir de los logros ya alcanzados en esta materia. En mi opinión para el adecuado progreso en esta área de la Filología Griega se debe producir una convergencia entre, por un lado, los aportes procedentes de la lexicografía general o del trabajo en lexicografía fuera del ámbito del griego antiguo y, por otro, los avances en

31 Sobre los problemas que plantea la inclusión de clichés y frases hechas me parecen especialmente interesantes los siguientes trabajos: P. Bogaards, «À la recherche de collocations dans le dictionnaire de langue étrangère», en: R. Lorenzo (ed.), Actas do XIX Congreso Internacional de Lingüistica e Filoloxía Románicas, vol. II Lexicología e Metalexicografía, La Coruña, 1992, pp. 179-184.; R. H. Gows, «Idioms and collocations in bilingual dictionaries and their Afrikaans translation equivalents», Lexicographica 12, 1996, pp. 54-88. 
otras áreas de la Filología Griega y las Ciencias de la Antigüedad, en general. En este trabajo este último aspecto ha quedado ejemplificado con la crítica textual y de forma similar se podría analizar cómo líneas de investigación recientes en la sintaxis del griego antiguo se pueden aprovechar para el trabajo en lexicografía griega, al igual que los avances y aportaciones en áreas como la Arqueología y la Historia, que resultan fundamentales para la redacción de los artículos de realia ${ }^{32}$, la Dialectología o los Estudios Literarios, por mencionar tan solo algunas. El trabajo lexicográfico no puede concebirse como una actividad cerrada sobre sí misma, sino que debe incorporar todas estas aportaciones sometiéndolas, claro está, a su propia metodología.

32 Por mencionar tan solo un ejemplo en un área diferente del griego, la interrelación entre lexicografía y arqueología e historia se pone claramente en evidencia en el trabajo de C. P. Biggam, «Grund to hrof: aspects of the Old English semantics of building and architecture», en: J. Coleman - C. J. Kay (eds.), Lexicology, Semantics and Lexicography, Amsterdam y Filadelfia, 2000, pp. 103-125. 